\title{
(2) OPEN ACCESS
}

\section{Global epidemiology of Neisseria gonorrhoeae in infertile populations: systematic review, meta- analysis and metaregression}

\author{
Hiam Chemaitelly, ${ }^{1}$ Alzahraa Majed, ${ }^{1}$ Farah Abu-Hijleh, ${ }^{2}$ Karel Blondeel, ${ }^{3,4}$ \\ Thabo Christopher Matsaseng, ${ }^{3,5}$ James Kiarie, ${ }^{3}$ Igor Toskin, ${ }^{3}$ Laith J Abu-Raddad (1) 1,6
}

- Additional material is published online only. To view, please visit the journal online (http://dx.doi.org/10.1136/ sextrans-2020-054515).

For numbered affiliations see end of article.

\section{Correspondence to}

Mrs Hiam Chemaitelly and Dr Laith J Abu-Raddad, Infectious Disease Epidemiology Group, Weill Cornell MedicineQatar, Cornell University, Qatar-Foundation, Education City, Doha 24144, Qatar; hsc2001@qatar-med.cornell. edu, lja2002@qatar-med. cornell.edu and Dr Igor Toskin, Department of Reproductive Health and Research, World Health Organization, Geneva, Switzerland; toskini@who.int

Received 5 April 2020 Accepted 14 April 2020 Published Online First 18 May 2020
Check for updates

(C) Author(s) (or their employer(s)) 2021. Re-use permitted under CC BY-NC. No commercial re-use. See rights and permissions. Published by BMJ.

\begin{tabular}{l}
\hline To cite: Chemaitelly $\mathrm{H}_{\text {, }}$ \\
Majed A, Abu-Hijleh F, \\
et al. Sex Transm Infect \\
2021:97:157-169. \\
\hline
\end{tabular}

\section{ABSTRACT}

Objective To provide an in-depth systematic assessment of the global epidemiology of gonorrhoea infection in infertile populations.

Methods A systematic literature review was conducted up to 29 April 2019 on international databases and WHO regional databases, and reported following Preferred Reporting Items for Systematic Reviews and Meta-Analyses guidelines. All prevalence measures of gonorrhoea infection among infertile populations, based on primary data, qualified for inclusion. Infertile populations were broadly defined to encompass women/men undergoing infertility evaluation or treatment (infertility clinic attendees and partners). Pooled mean prevalence by relevant strata was estimated using random-effects meta-analysis. Associations with prevalence and sources of heterogeneity were explored using metaregression. Risk of bias was assessed using four quality domains.

Findings A total of 147 gonorrhoea prevalence studies were identified from 56 countries. The pooled mean prevalence of current gonorrhoea infection was estimated globally at $2.2 \%(95 \% \mathrm{Cl} 1.3 \%$ to $3.2 \%)$, with the highest prevalence in Africa at $5.0 \%(95 \% \mathrm{Cl}$ $1.9 \%$ to $9.3 \%)$. The mean prevalence was higher for populations with tubal factor infertility $(3.6 \%, 95 \%$ $\mathrm{Cl} 0.9 \%-7.7 \%)$ and mixed cause and unexplained infertility (3.6\%, 95\% Cl 0.0\% to $11.6 \%$ ) compared with other diagnoses, such as ovarian and non-tubal infertility $(0.1 \%, 95 \% \mathrm{Cl} 0.0 \%$ to $0.8 \%)$, and for secondary $(2.5 \%, 95 \% \mathrm{Cl} 0.2 \%$ to $6.5 \%)$ compared with primary $(0.5 \%, 95 \% \mathrm{Cl} 0.0 \%$ to $1.7 \%)$ infertility. Metaregression identified evidence of variations in prevalence by region and by infertility diagnosis, higher prevalence in women than men and a smallstudy effect. There was a trend of declining prevalence by about $3 \%$ per year over the last four decades ( $O R=0.97,95 \% \mathrm{Cl} 0.95$ to 0.99 ).

Conclusions Gonorrhoea prevalence in infertile populations is several folds higher than that in the general population, with even higher prevalence in women with tubal factor infertility and in individuals with secondary infertility. These findings support the potential role of gonorrhoea in infertility and suggest that some infertility is possibly preventable by controlling gonorrhoea transmission.

PROSPERO registration number CRD42018102934.

\section{INTRODUCTION}

Infertility, 'a disease characterised by failure to establish clinical pregnancy after 12 months of regular, unprotected sexual intercourse', ${ }^{12}$ affects $\sim 2 \%$ of reproductive-age women with no prior live birth and $>10 \%$ of those with an earlier successful delivery. ${ }^{3}$ While infertility in men remains poorly quantified, ${ }^{4}$ available estimates by world region suggest a range of $2.5 \%-12.0 \%{ }^{5}$

A potential contributor to infertility, for both women and men, is a common STI caused by the bacterium Neisseria gonorrhoeae, ${ }^{6}$ in addition to Chlamydia trachomatis (CT)..$^{7-10}$ In 2016, the WHO estimated that nearly 87 million individuals acquired this infection globally, with incidence rates estimated at 20 per 1000 women and 26 per 1000 men. ${ }^{11}$ In women, gonorrhoea is often asymptomatic, complicating early detection and treatment and increasing their risk of cervicitis and pelvic inflammatory disease, ${ }^{12} 13$ while in men, it has been associated with epididymitis, epididymo-orchitis and chronic prostatitis. ${ }^{14-17}$ Untreated, these conditions may lead to subfertility/infertility. ${ }^{12} 141518$

Despite their health, social and economic implications, ${ }^{19}{ }^{20}$ STIs and infertility have long been a low priority on national policy agendas. Recently, the WHO formulated the 'Global Health Sector Strategy on STIs, 2016-2021', with the goal of ending STI epidemics as a public health concern by $2030 .^{21}$ A key target is achieving by 2030 a $90 \%$ reduction in N. gonorrhoeae incidence. ${ }^{21}$ The urgency in addressing gonorrhoea is compounded by its recent classification as a 'superbug,, 22 given the widespread antimicrobial resistance, even to infection's last-line treatment. ${ }^{23-26}$ Consequently, the WHO launched a global action plan to control gonorrhoea transmission and sequelae, ${ }^{27} 28$ including building a business case for the global public health value of gonococcal vaccines. ${ }^{29} 30$ Achieving WHO set targets entails fulfilment of five strategic directions/actions; the first is to understand the STI epidemic and burden, including subfertility/ infertility, as a basis for advocacy, political commitment, national planning, resource mobilisation and allocation, implementation and programme improvement. $^{21}$

This study was motivated by our recent work assessing CT prevalence levels in different at-risk populations in the Middle East and North Africa, 
where we identified an association between CT prevalence and infertility, with prevalence among infertile populations being three-fold higher than that among the general population. ${ }^{10}$ The present study aimed to characterise the global epidemiology of gonorrhoea infection in infertile populations by (1) systematically reviewing and synthesising evidence of infection prevalence, (2) estimating the pooled mean prevalence, stratified by WHO region among other key factors, and (3) exploring populationlevel associations with prevalence and sources of between-study heterogeneity.

Longitudinal studies examining gonorrhoea's adverse health outcomes (a curable infection) are difficult/unethical to conduct. A recent study attempted to overcome this challenge through linking national testing databases to hospital records, but identified too few cases to reach conclusive evidence about gonorrhoea's role in infertility. ${ }^{31}$ In the absence of direct evidence, our study aimed to provide indirect evidence for a link between gonorrhoea and infertility but strictly did not aim to nor can it establish causality. The underlying hypothesis is that current infection is of unknown duration and persistence to establish a causal link with infertility, but is often predictive of past exposure. ${ }^{32-34}$ This assertion is supported by several lines of evidence. It is established through tens of studies of different designs that gonorrhoea as well as chlamydia, being curable infections, carry a high risk of reinfection because of re-exposure to the same sexual partner or to other high-risk partners. ${ }^{33} 35-37$ As such, it can be assumed that a current gonorrhoea infection is strongly indicative of a previous gonorrhoea infection ${ }^{33} 3839$; indeed studies have shown that the strongest predictor of current gonorrhoea infection is a history of gonorrhoea infection. ${ }^{32}{ }^{40}$ For example, in the UK, a history of gonorrhoea infection was found to be the strongest predictor of current gonorrhoea infection even after controlling for other demographic and behavioural factors (adjusted OR 4.36, 95\% CI 1.78 to 10.71 ). ${ }^{32}$

It is also established that there are strong correlations between exposure and the prevalence of different STIs, such as gonorrhoea and chlamydia, ${ }^{41} 42$ herpes simplex virus type 2 (HSV-2) and HIV $^{43-45}$ (beyond the debated biological synergy ${ }^{46}$ ), even though these STIs could be acquired at different time frames. As such, exposure to an STI is a predictor of exposure to another STI. For instance, HSV-2 is often used as a proxy biomarker for HIV exposure and epidemic potential. ${ }^{43-45}$ Just as STI exposures acquired at different time points are correlated with each other, it is reasonable to expect that measures of gonorrhoea prevalence assessed at different times in the same population are also correlated. ${ }^{3240}$ This is because, fundamentally, the driving factor of STI exposure is sexual risk behaviour ${ }^{47}$; current gonorrhoea infection in a population/person can be seen as a proxy of the past and present sexual risk behaviour of that population/person or person's sexual partners. ${ }^{48} 49$ Studies also show that people tend to be consistent in their sexual risk behaviour over at least a few years' duration. ${ }^{50-52}$

\section{METHODS}

Detailed methodology has been previously published as a study protocol. ${ }^{53}$ A brief description is provided as follows.

\section{Search strategy and selection criteria}

A systematic review of gonorrhoea prevalence in infertile populations was conducted following Cochrane Collaboration guidelines, ${ }^{54}$ and reported following the Preferred Reporting Items for Systematic Reviews and Meta-Analyses guidelines ${ }^{55}$ (checklist in online supplementary table 1).
Literature was searched, up to 29 April 2019 on PubMed and Embase, and up to 5 February 2019 on the WHO Index Medicus regional databases, using broad terms with no language or year restrictions (online supplementary box 1). Duplicate citations were excluded using a reference manager, EndNote (Thomson Reuters, USA). Title and abstract screening and full-text screening of relevant/potentially relevant citations were performed by HC and AM. Reference lists of reviews and relevant articles were further hand-searched.

Any article reporting prevalence of current urogenital infection or serological markers of gonorrhoea in infertile populations, based on primary data, qualified for inclusion. Infertile populations were broadly defined to include women/men undergoing infertility evaluation or treatment (infertility clinic attendees and partners). Studies in voluntarily sterile populations, based on the infection's self-report, including $<10$ participants, or assessing gonorrhoea in tissue samples from the upper genital tract, were excluded.

\section{Data extraction and synthesis}

Data were extracted by HC and AM and double extracted by FA (extraction list in online supplementary box 2). In addition to the overall gonorrhoea measure, stratified measures were extracted whenever a stratum included $\geq 10$ participants.

Studies assessing gonorrhoea using different assay types (nucleic acid amplification test (NAAT), culture, Gram stain and Ig among others) were extracted separately for different analyses. Studies applying the same assay to different biological specimens were included once based on a predefined order prioritising, for women, gonorrhoea detection in endocervical swabs, followed by vaginal and urine samples; and for men, detection in urethral swabs, followed by urine and semen samples.

\section{Risk of bias and precision assessments}

Informed by the Cochrane approach ${ }^{54}$ and existing literature ${ }^{56-59}$ each study was rated as having 'low' versus 'high' risk of bias on four quality domains: (1) validity of infertility definition (follows WHO definition vs otherwise), (2) lack of exposure to antimicrobials for $\geq 1$ week prior to collection of biological samples (ascertained vs otherwise), (3) consistency in assay used for infection ascertainment (same assay used to test all participants vs otherwise) and (4) response rate ( $\geq 80 \%$ vs $<80 \%)$. A study with missing information for a specific domain was considered as having 'unclear' risk of bias for that domain. A study was deemed of 'higher' precision if its original sample tested $\geq 100$ participants.

\section{Meta-analysis}

Pooled mean gonorrhoea prevalence and 95\% CIs were estimated using random-effects meta-analysis. Here, overall prevalence was replaced by strata, whenever possible. For each study, only one final stratification was considered, based on a predefined priority order: country, sex, infertility diagnosis, infertility type, age and year of data collection. Stratified metaanalyses by relevant factors were further performed, and heterogeneity assessment was conducted. ${ }^{6061}$

\section{Metaregression}

Metaregression analyses were conducted to explore sources of between-study heterogeneity and to examine associations with prevalence for the following predefined factors: WHO region (African region (AFRO), Americas (AMRO), Eastern Mediterranean (EMRO), European (EURO), Southeast Asia (SEARO), 


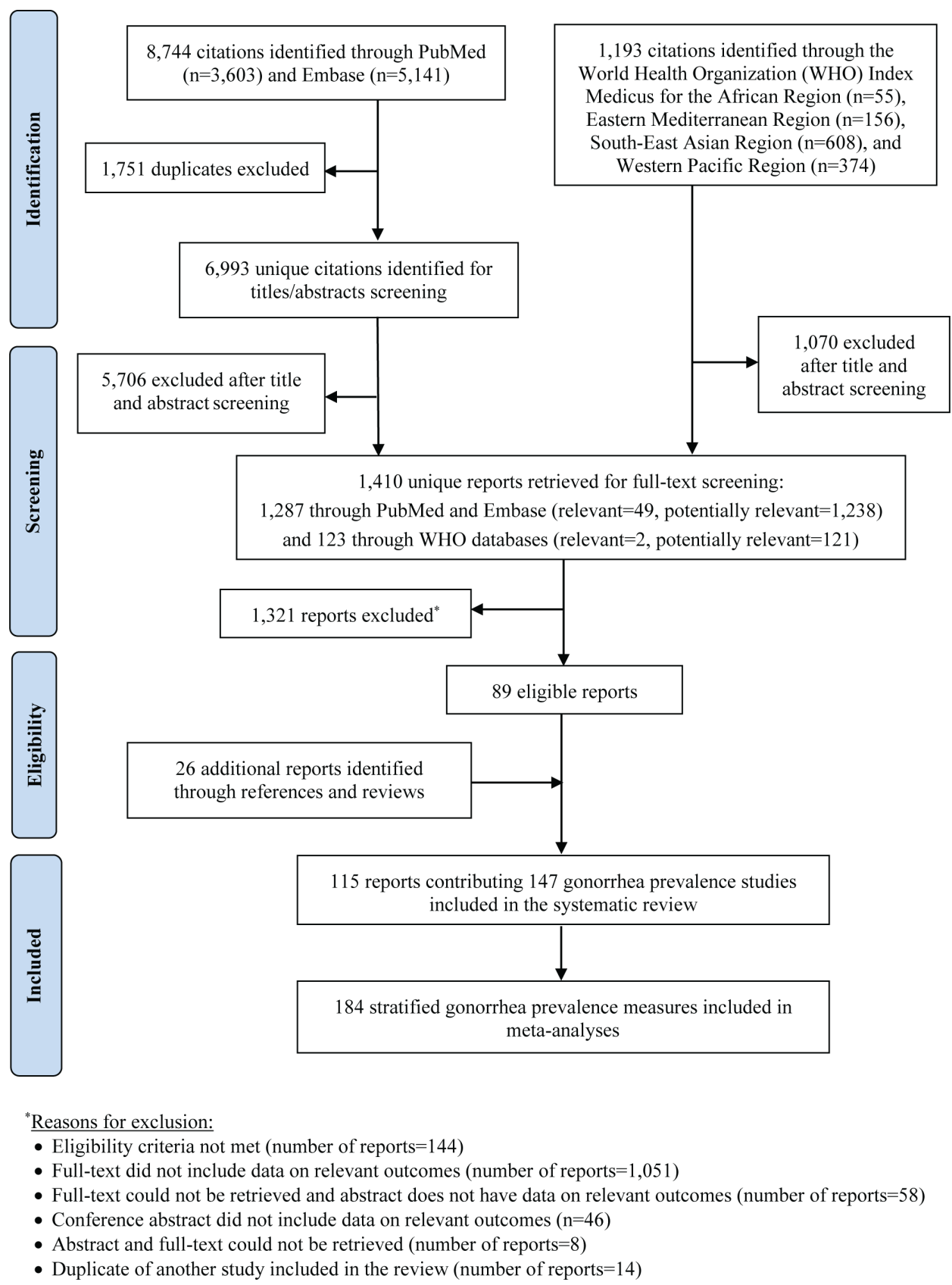

Figure 1 Flowchart of the study selection process for the global systematic review of Neisseria gonorrhoeae infection prevalence in infertile populations, following the Preferred Reporting Items for Systematic Reviews and Meta-Analyses guidelines..$^{55}$

Western Pacific (WPRO)), sex, infertility type, infertility diagnosis, presence of urogenital signs and symptoms, assay type, median year of data collection, sample size/precision (to assess small-study effect) and risk of bias domains. Variables' details/ subgroupings are in online supplementary box 2 and online supplementary table 2 .

Strength of evidence for an association with prevalence was deemed 'good' at $0.05<\mathrm{p}$ value $\leq 0.10$ and 'strong' at $\mathrm{p}$ value $\leq 0.05$. Sensitivity analysis focusing on studies assessing current infection was performed.

\section{RESULTS}

\section{Search results and scope of evidence}

Figure 1 shows the study selection process. Search identified 9937 citations: 3603 through PubMed, 5141 through Embase and 1193 through the WHO Index Medicus databases. After excluding duplicates and screening titles and abstracts, 1410 unique reports underwent full-text screening. Of these, 89 were eligible for inclusion. The rest were excluded for reasons outlined in figure 1 . Twenty-six additional reports were identified through reference list hand-searching. In sum, 115 reports contributing 147 gonorrhoea prevalence studies were included in the review. These yielded 184 stratified measures for meta-analyses.

There were 27264 gonorrhoea test results from 56 countries. EURO contributed $44.2 \%$ of studies $(\mathrm{n}=65)$, AMRO $16.3 \%$ $(\mathrm{n}=24)$, AFRO 13.6\% $(\mathrm{n}=20)$, SEARO 8.2\% $(\mathrm{n}=12)$, WPRO and EMRO $7.5 \%(\mathrm{n}=11)$ each, and multicentre/multiregional studies $2.7 \%(\mathrm{n}=4)$. Most studies $(\mathrm{n}=107,72.8 \%)$ assessed current infection, of which $26.2 \%$ were NAAT-based; $67.3 \%$ were culture-based; and 6.5\%were Gram stain/gonozyme/ 
fluorescent antibody-based. The rest either reported ever infection using $\operatorname{IgG}(n=20,13.6 \%)$ or $\operatorname{IgA}(n=3,2.0 \%)$, or were based on unclear assays $(n=17,11.6 \%)$. Studies are detailed in online supplementary tables 3-8.

\section{Prevalence overview}

Reported current infection prevalence across regions ranged from $0 \%$ to $53.0 \%$ (online supplementary tables $3-8$ ). The median was $0 \%$, as 57 out of 107 studies reported zero prevalence; it is difficult to identify a positive case for a low-prevalence infection in a study of a small sample size. The highest median current infection prevalence was for AFRO at 3.3\%. Ever infection prevalence (IgG) ranged from $1.3 \%$ to $65.0 \%$, with a median of $25.0 \%$; the median per region ranged from $2.5 \%$ in EMRO to $39.1 \%$ in AFRO (online supplementary tables 3-8).

\section{Risk of bias and precision assessments}

Online supplementary tables 9 and 10 show the summarised and study-specific precision and risk of bias assessments. Briefly, $50.3 \%$ of studies were of higher precision ( $\geq 100$ participants). Over a third (34.7\%) followed WHO infertility definition; $1.3 \%$ included infertile participants for $<12$ months, while the rest $(64.0 \%)$ did not report an infertility definition. Only $14.3 \%$ of studies excluded infertile participants exposed to antimicrobials in the week prior to sample collection; $6.1 \%$ may have included such participants; and information was missing for the rest of studies (79.6\%). Almost all studies (96.6\%) demonstrated consistency in gonorrhoea testing across infertile participants. Response rate was mostly unavailable (97.3\%); studies were almost entirely facility/clinic-based or retrospective charts were review-based.

Studies were overall of reasonable quality (online supplementary table 9$)$. Nearly all (98.6\%) had low risk of bias in $\geq 1$ quality domain and $41.5 \%$ had low risk of bias in $\geq 2$ domains. Meanwhile, only $8.8 \%$ had high risk of bias in $\geq 1$ quality domain and $<1 \%$ had high risk of bias in $\geq 2$ domains. Over $90 \%$ of studies had unclear risk of bias in $\geq 2$ domains.

\section{Summary estimates of pooled mean gonorrhea prevalence}

Forest plots showing meta-analysis results for studies reporting current infection prevalence, by relevant strata, are in figure 2 and online supplementary figures 1-14.

Pooled mean prevalence of current gonorrhoea infection was globally at $2.2 \%$ (95\% CI $1.3 \%$ to $3.2 \%)$, and regionally at $5.0 \%$ (95\% CI $1.9 \%$ to $9.3 \%$ ) in AFRO, $2.7 \%$ (95\% CI $0.6 \%$ to $5.8 \%)$ in EMRO, $2.5 \%$ (95\% CI $0.4 \%$ to $5.7 \%)$ in WPRO, $2.4 \%(95 \%$ CI $0.8 \%$ to $4.5 \%)$ in EURO, $1.0 \%$ (95\% CI $0.0 \%$ to $3.4 \%$ ) in AMRO and $0.0 \%$ (95\% CI $0.0 \%$ to $0.06 \%$ ) in SEARO (table 1 ). Meanwhile, mean ever infection prevalence was globally at $21.0 \%$ (95\% CI $13.2 \%$ to $30.0 \%$ ) and varied regionally from $5.4 \%$ (95\% CI $1.2 \%$ to $12.0 \%$ ) in AMRO to $46.6 \%$ (95\% CI $28.4 \%$ to $65.3 \%$ ) in AFRO (table 1 ).

Estimates varied by infertility diagnosis (table 1). Mean current infection prevalence was 3.6\% (95\% CI $0.9 \%$ to $7.7 \%$ ) for tubal factor infertility (TFI), 3.6\% (95\% CI $0.0 \%$ to $11.6 \%$ ) for mixed (samples combining different diagnoses) and unexplained infertility, $2.6 \%$ (95\% CI $1.1 \%$ to $4.5 \%$ ) for general/unspecified infertility, $1.4 \%$ (95\% CI $0.2 \%$ to $3.3 \%$ ) for male factor infertility and $0.06 \%(95 \%$ CI $0.0 \%$ to $0.8 \%)$ for ovarian and non-TFI infertility. This measure was also $2.5 \%$ for secondary infertility (95\% CI $0.2 \%$ to $6.5 \%)$ and $0.5 \%$ for primary infertility $(95 \%$ CI $0.0 \%$ to $1.7 \%)$.
Mean current infection prevalence varied by assay type: $0.7 \%$ (95\% CI $0.08 \%$ to $1.6 \%$ ) using NAAT, $2.7 \%$ (95\% CI $1.4 \%$ to $4.3 \%$ ) using culture, $3.8 \%$ (95\% CI $0.0 \%$ to $24.4 \%$ ) using other assays assessing current infection and $8.7 \%$ (95\% CI $0.0 \%$ to 31.3\%) using Gram stain (table 1).

Mean current infection prevalence was $2.5 \%$ in women $(95 \%$ CI $1.2 \%$ to $4.1 \%$ ) vs $1.5 \%$ in men (95\% CI $0.5 \%$ to $3.0 \%), 3.0 \%$ in studies before 2005 (95\% CI $1.5 \%$ to $4.8 \%$ ) vs $1.1 \%$ in those after 2005 (95\% CI $0.4 \%$ to 2.0\%), 4.1\% in samples including $<100$ participants (95\% CI $1.8 \%$ to $6.9 \%$ ) vs $1.0 \%$ in those including $\geq 100$ participants (95\% CI $0.3 \%$ to $1.9 \%$ ) and $16.2 \%$ in symptomatic individuals (95\% CI $7.1 \%$ to $27.7 \%)$ vs $1.0 \%$ in asymptomatic ones (95\% CI $0.3 \%$ to $2.0 \%$ ) (table 1 ).

Mean ever infection prevalence showed similar results, although at much higher prevalence levels (table 1).

There was evidence for heterogeneity in prevalence across studies. Most meta-analyses showed a $\mathrm{p}$ value of $<0.001$ for Cochran's Q statistic, wide prediction intervals indicating high heterogeneity and $\mathrm{I}^{2} \geq 70 \%$, affirming most variability as due to true differences in prevalence across studies rather than chance (table 1).

\section{Associations with prevalence and sources of between-study heterogeneity}

Univariable metaregression results are in table 2. There was 'strong' evidence for an association with prevalence ( $p$ value of $\leq 0.05$ ) for WHO region, sex, infertility diagnosis, presence of urogenital signs and symptoms, assay type, year of data collection, sample size and exposure to antimicrobials prior to sample collection; 'good' evidence for infertility type $(0.05<\mathrm{p}$ value $\leq 0.10)$, but no evidence for validity of infertility definition, consistency in assay used for infection ascertainment and response rate.

Compared with AMRO, AFRO showed four-fold higher odds of gonorrhoea infection $(\mathrm{OR}=4.0,95 \% \mathrm{CI} 1.5$ to 10.1$)$, while no significant differences were found for the other regions. Women had twice higher odds of infection than men $(\mathrm{OR}=2.0$, 95\% CI 1.1 to 3.7$)$. Individuals with secondary infertility also had twice higher odds of infection $(\mathrm{OR}=2.1,95 \% \mathrm{CI} 0.9$ to 5.2) than those with primary infertility. Odds were 2.4-fold (95\% CI 1.2 to 4.6 ) and 2.0-fold (95\% CI 0.8 to 5.0) higher for women with TFI and for individuals with mixed cause and unexplained infertility, respectively, compared with those with general/unspecified infertility. Symptomatic individuals had sixfold higher odds of infection compared with asymptomatic ones $(\mathrm{OR}=5.9,95 \%$ CI 2.6 to 13.5$)$.

Culture and other assays detecting current infection showed 2.5 -fold (95\% CI 1.3 to 4.8 ) and 4.1-fold (95\% CI 1.1 to 15.3 ) higher odds, respectively, compared with NAAT, while assays detecting IgG showed 22.1-fold higher odds (95\% CI 9.5 to 51.2). There was evidence for declining prevalence at $\sim 3 \%$ per year over the last four decades $(\mathrm{OR}=0.97,95 \% \mathrm{CI} 0.95$ to 0.99$)$ and for small-study effect, with studies including $\geq 100$ participants showing lower prevalence $(\mathrm{OR}=0.5,95 \% \mathrm{CI} 0.3$ to 0.9$)$.

Sensitivity analysis using only studies assessing current gonorrhoea infection affirmed the aforementioned results, although some associations failed to reach statistical significance because of the smaller number of studies (online supplementary table 11).

Full multivariable metaregression analysis could not be performed due to lack of statistical power. ${ }^{62}$ However, backward variable selection yielded a final multivariable model including four predictors: region, presence of urogenital signs and 
A

African Region

Author, Year

NG positive Sample size

Events per 100

Ogunbanjo, 1989

Muvunyi, 2011

Collet, 1988

Hoosen, 1996

Okonofua, 1995

Walraven, 2001

Mandara, 1980

Faye-Kette, 1995

Duba, 2017

Cohen, 2000

Nsonwu-Anyanwu, 2011

Arowojolu, 1998

Collet, 1988

Arya, 1980

Okonofua, 1995

Walraven, 2001

Random effects mode

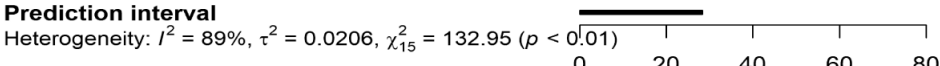

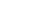

observations

W(Random) Prev(\%) $\quad 95 \% \mathrm{Cl}$

Prevalence of current gonorrhea infection $(95 \% \mathrm{Cl})$

$7.6 \% \quad 1.53 \quad[0.80 ; 2.67]$

$7.4 \% \quad 4.13 \quad[2.00 ; 7.47]$

$7.2 \% \quad 5.52 \quad[2.68 ; 9.93]$

$6.7 \% \quad 17.14[0.18 ; 28.03]$

$\begin{array}{rr}6.6 \% & 17.14 \\ 6.5 \% & 0.00 \quad[0.00 ; 5.44]\end{array}$

$6.5 \% \quad 4.69 \quad[0.98 ; 13.09]$

$6.4 \% \quad 25.86[15.26 ; 39.04]$

$6.3 \% \quad 0.00 \quad[0.00 ; 6.98]$

$6.2 \% \quad 0.00 \quad[0.00 ; 7.55]$

$5.9 \% \quad 0.00 \quad[0.00 ; 8.81]$

$5.9 \% \quad 46.15[30.09 ; 62.82]$

$5.9 \% \quad 0.00 \quad[0.00 ; 9.25]$

$5.5 \% \quad 10.00 \quad[2.11 ; 26.53]$

$5.0 \% \quad 18.18 \quad[5.19 ; 40.28]$

$4.3 \% \quad 0.00 \quad[0.00 ; 21.80]$

$100.0 \%$

$5.03[1.87 ; 9.33]$

$[0.00 ; 28.31]$

B

Tubal factor infertility

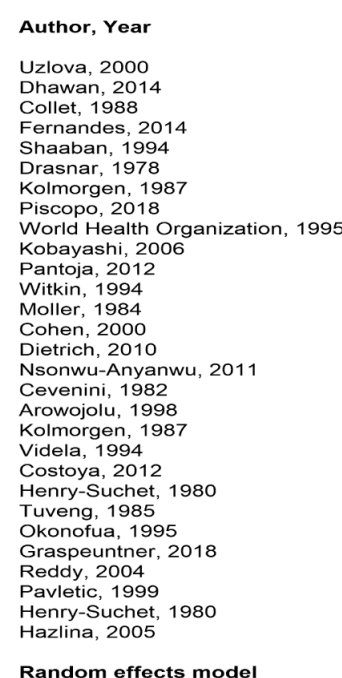

NG positive Sample size

Events per 100

W(Random) Prev(\%) $\quad 95 \% \mathrm{Cl}$

Random effects mode

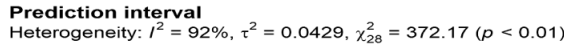

$\begin{array}{rr}1 & 36 \\ 1 & 25 \\ 10 & 181\end{array}$

$250:$

181

$3.9 \% \quad 0.28 \quad[0.01 ; 1.53]$

$\begin{array}{llll}3.8 \% & 0.40 & {[0.01 ; 2.21]} \\ 3.8 \% & 5.52 & {[2.68 ; 9.93]}\end{array}$

$3.8 \% \quad 0.00 \quad[0.00 ; 2.40]$

. $7 \%$ $52.17[41.50 ; 62.70]$

$3.7 \% \quad 21.59[13.53 ; 31.65]$

$3.7 \% \quad 0.00 \quad[0.00 ; 4.35]$

$3.7 \% \quad 2.56 \quad[0.31 ; 8.96]$

$\begin{array}{llll}3.6 \% & 0.00 & {[0.00 ; 5.28]} \\ 3.6 \% & 0.00 & {[0.00 ; 5.69]}\end{array}$

$3.6 \% \quad 0.00 \quad[0.00 ; 5.96]$

$3.5 \% \quad 0.00 \quad[0.00 ; 7.25]$

$3.5 \% \quad 0.00 \quad[0.00 ; 7.55]$

$3.4 \% \quad 0.00 \quad[0.00 ; 8.81]$

$\left.\begin{array}{llll}3.4 \% & 0.00 & {[0.00 ; 8.81}\end{array}\right]$

$\begin{array}{rrr}3.4 \% & 0.00 \quad[0.00 ; 8.81] \\ 3.4 \% & 46.15 & {[30.09 ; 62.82]}\end{array}$

$3.4 \% \quad 28.95[15.42 ; 45.90]$

$\left.\begin{array}{rr}3.1 \% & 3.12\end{array}\right][0.08 ; 16.22]$

$3.3 \% \quad 0.00 \quad$ [ $0.00 ; 11.94]$

$3.1 \% \quad 0.00 \quad[0.00 ; 15.44$

$3.1 \%$ O.00 [0.00: 16.11$]$

$3.0 \% \quad 0.00 \quad$ [ $0.00 ; 17.65]$

$3.0 \% 52.63$ [28.86; 75.55$]$

$\begin{array}{lll}3.0 \% & 0.00 & {[0.00 ; 19.51]} \\ 2.8 \% & 0.00 & {[0.00 ; 24.71]}\end{array}$

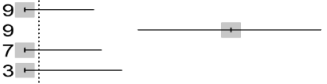

2145

$100.0 \%$

$3.61[0.85 ; 7.67]$

C

Secondary infertility

Author, Year

NG positive Sample size

Events per 100

observations

W(Random) Prev(\%) $\quad 95 \% \mathrm{Cl}$

Fernandes, 2014

Collet, 1988

Fernandes, 2014

Mares, 2009

Okonofua, 1995

Walraven, 2001

Pantoja, 2012

Kildea, 2000

Pantoja, 2012

Cohen, 2000

Dutta, 2008

Kundsin, 1986

Collet, 1988

Martens-1993

Videla, 1994

Okonofua, 1995

Random effects model

Prediction interval

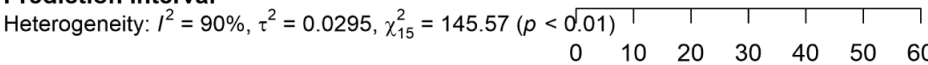

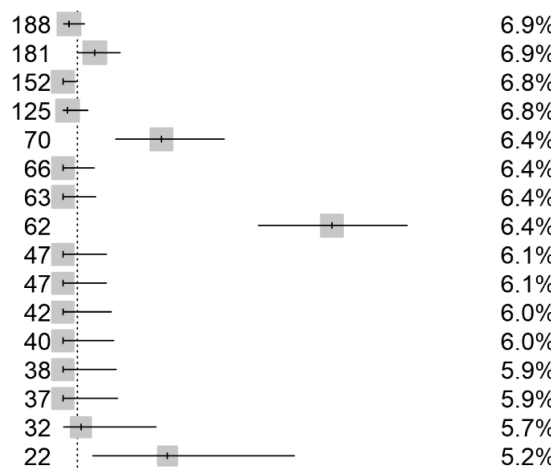

$6.9 \% \quad 1.06 \quad[0.13 ; 3.79]$

$5.52 \quad[2.68 ; 9.93]$

$0.8 \% \quad[0.00 ; 2.40]$

$0.80 \quad[0.02 ; 4.38]$

$17.14 \quad[9.18 ; 28.03]$

$0.00 \quad[0.00 ; 5.44]$

$6.4 \% \quad 0.00 \quad[0.00 ; 5.69]$

$6.4 \% \quad 46.77[33.98 ; 59.88]$

$6.1 \% \quad 0.00 \quad[0.00 ; 7.55]$

$6.1 \% \quad 0.00 \quad[0.00 ; 7.55]$

$0.00 \quad[0.00 ; 8.41]$

$6.0 \% \quad 0.00 \quad[0.00 ; 8.81]$

$0.00 \quad[0.00 ; 9.25]$

$0.00 \quad[0.00 ; 9.49]$

$\begin{array}{rrr}3.12 & {[0.08 ; 16.22]}\end{array}$

$100.0 \%$

2.45 [0.16; 6.46]

[ $0.00 ; 28.13]$

Prevalence of current gonorrhea infection $(95 \% \mathrm{Cl})$

Figure 2 Forest plots showing key results of the meta-analysis on studies reporting the prevalence of current NG infection in infertile populations for (A) the WHO -African Region, (B) tubal factor infertility and (C) secondary infertility. NG, Neisseria gonorrhoeae. 


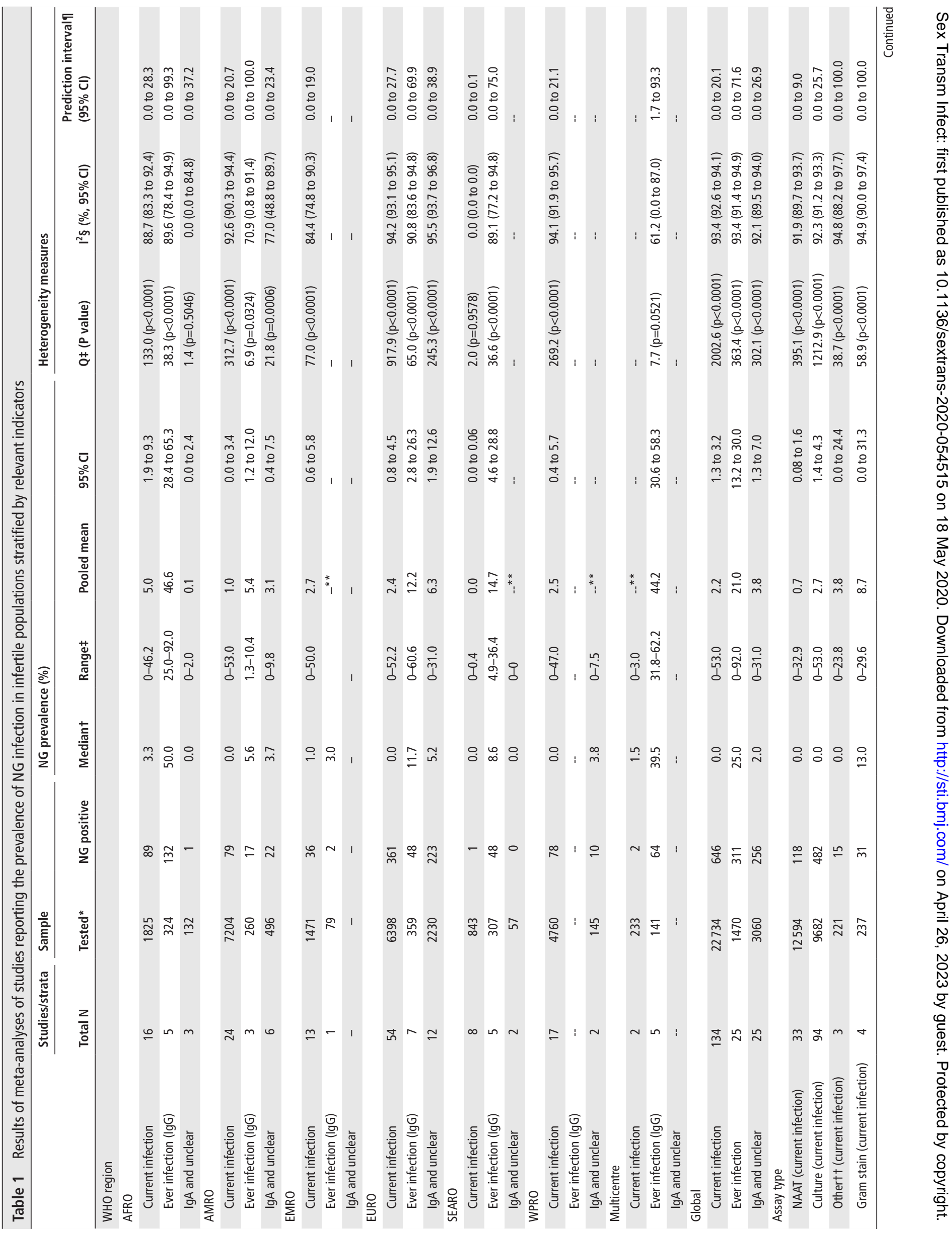




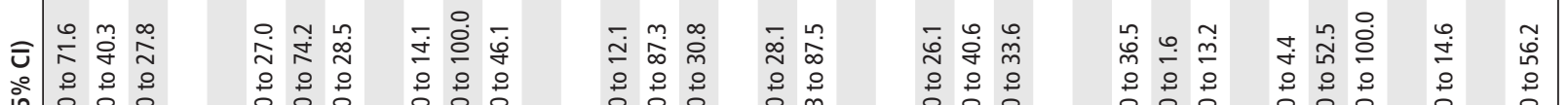

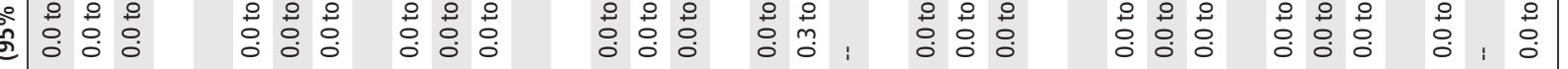

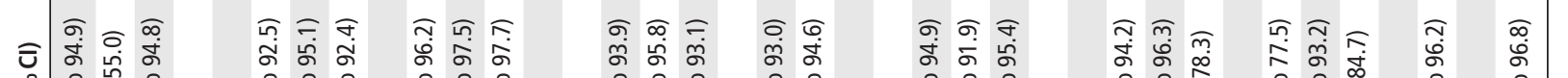

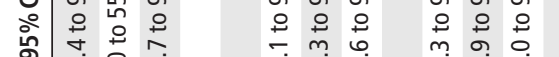
ㅇำ 00

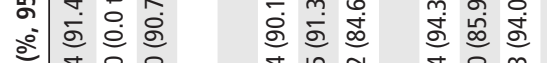

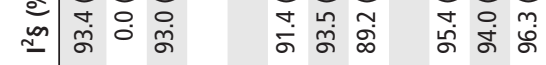

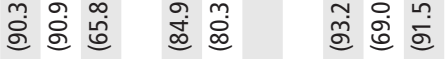

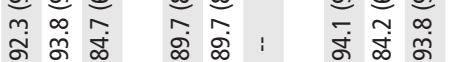

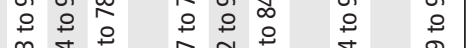

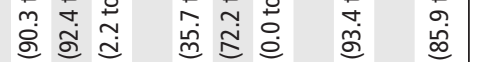

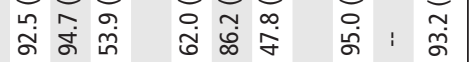

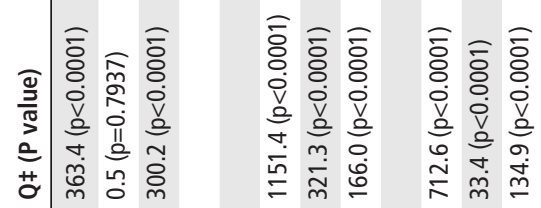

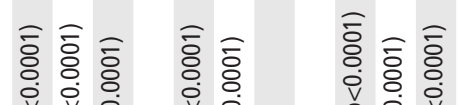

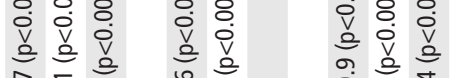

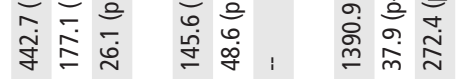

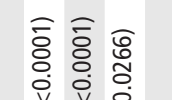
v v

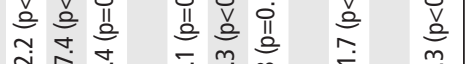

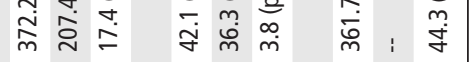

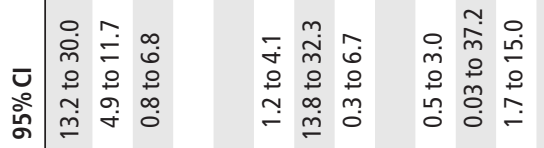

$\stackrel{\infty}{=} \stackrel{\infty}{m} \stackrel{m}{0}$ 占 $\stackrel{m}{0}=$

$=$\begin{tabular}{lll}
0 \\
\hdashline
\end{tabular} 궁

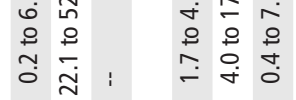
용

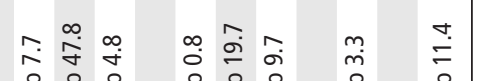

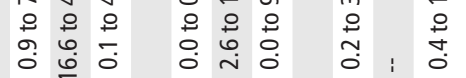

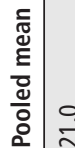

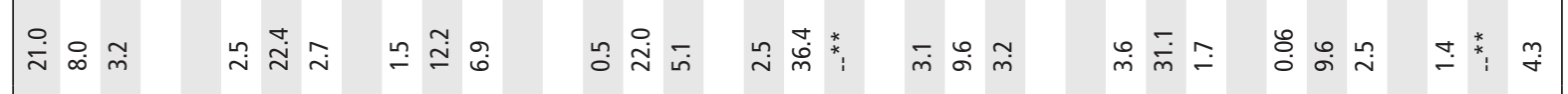

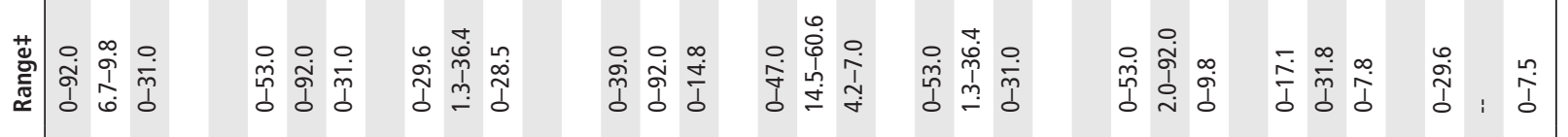

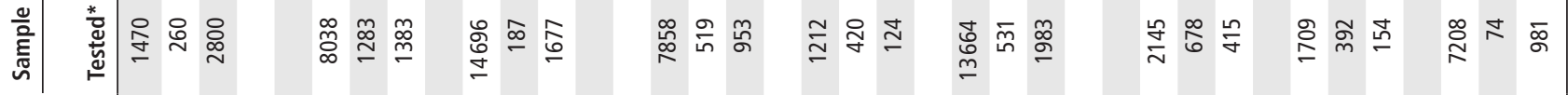
$\mid$

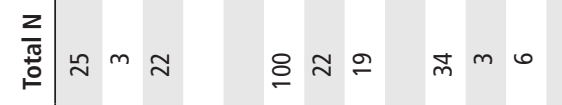
$\tilde{m} \simeq$ ก

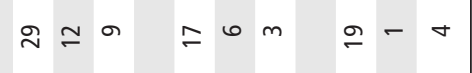

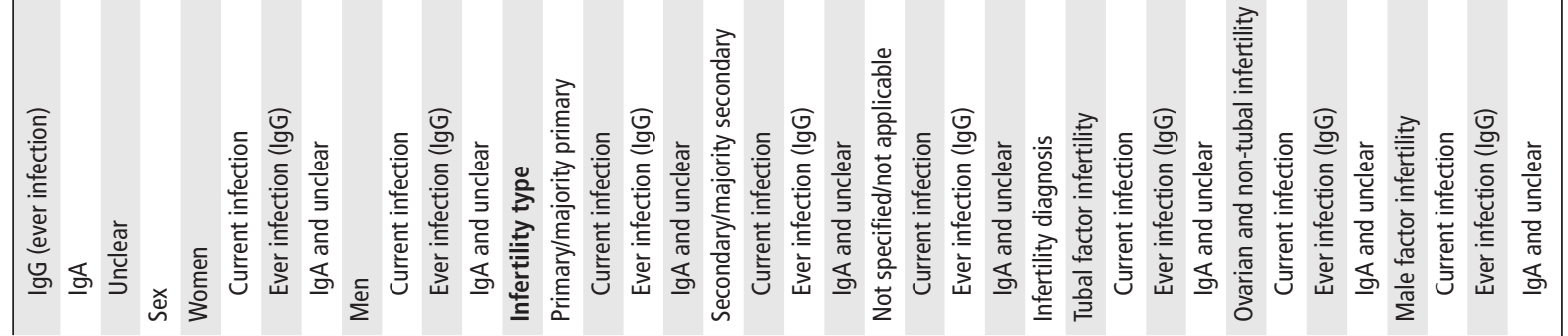


눙요

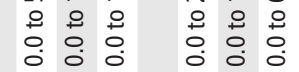

ิิ बूँ

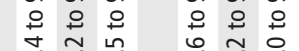

\&

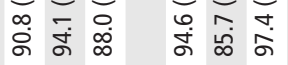

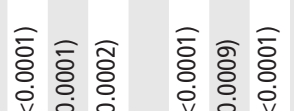

v v v il v v

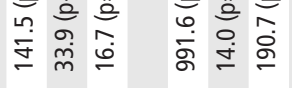

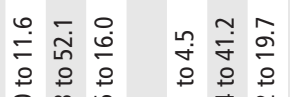

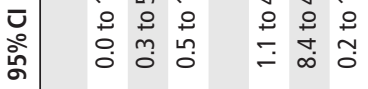

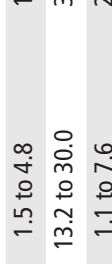

$\infty$

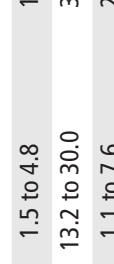

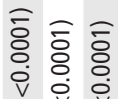

v

岕

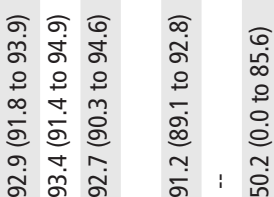

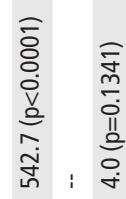

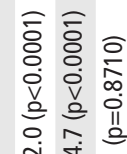

过

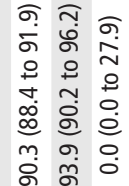

के

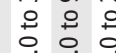

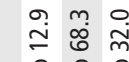

ํํำ

웅웅

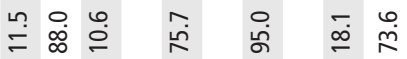

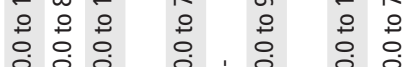

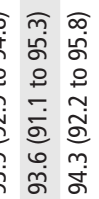

कूं हूं

$\widehat{m} \tilde{m} \hat{\infty}$

일

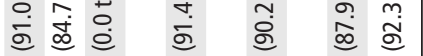
๙ूँ

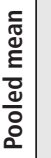

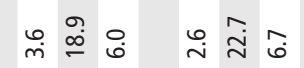

$\stackrel{\circ}{m} \stackrel{\circ}{\sim}$

$=\quad \stackrel{n}{m}$

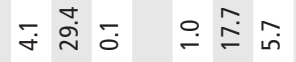

울욤

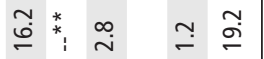

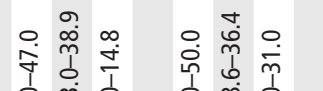

$\circ \circ \circ$

잉

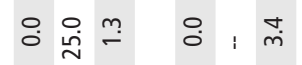

웅 尔 웅 웅

잉

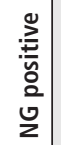

유 일 워 $\bar{m}$

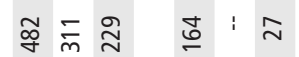

$\stackrel{m}{N} \sim \quad \underset{m}{\bar{n}}$ 出

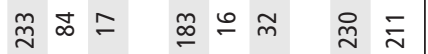

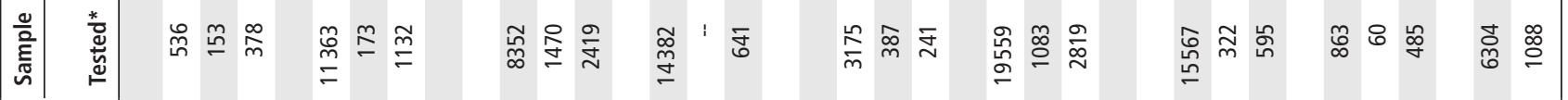

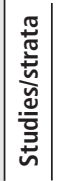

$\frac{2}{\substack{\frac{\pi}{0} \\ \frac{2}{\circ}}}$

$\pm m m \quad$ 占 $m o$

$\stackrel{\infty}{\infty} \stackrel{\sim}{\sim}$ ㅇ

누 $\infty$ \&

n $\sim$

$\stackrel{+}{2}+$

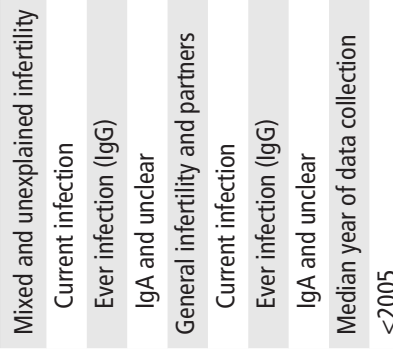

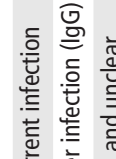

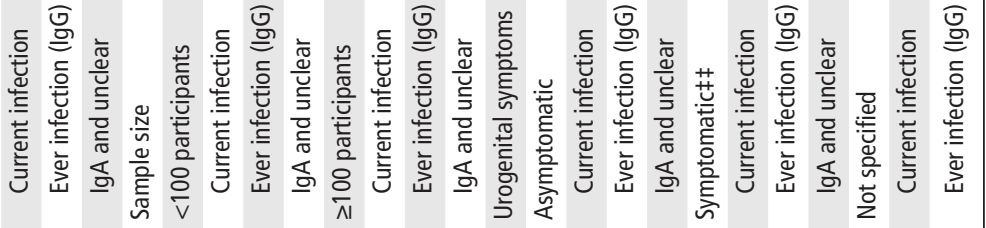




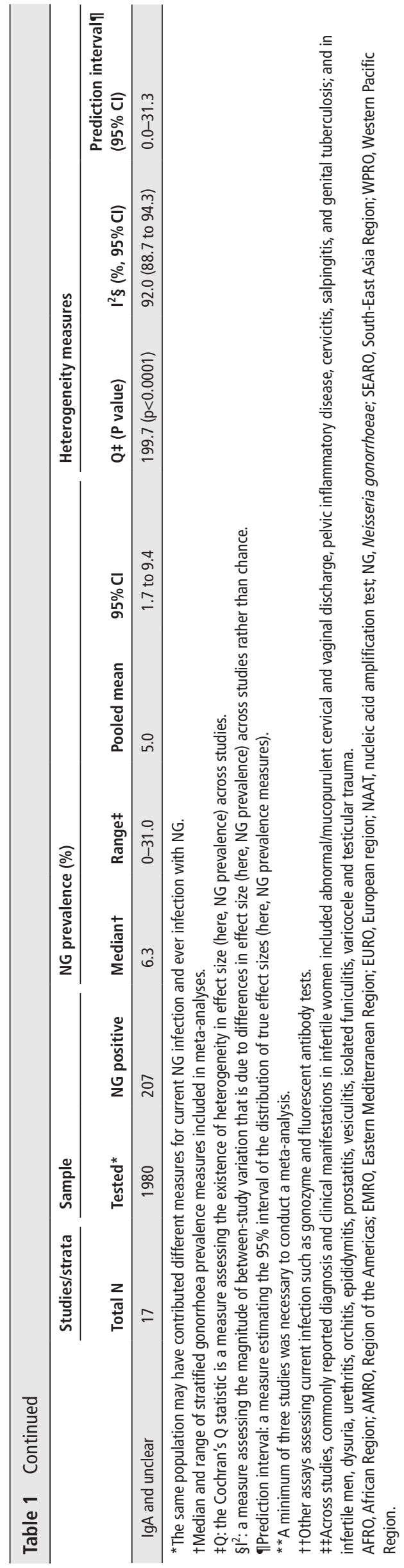

symptoms, sample size and assay type ( $\mathrm{p}$ value of $\leq 0.1$, online supplementary table 12). The analysis confirmed the univariable metaregression results.

\section{DISCUSSION}

We provided, to our knowledge, the first systematic review of gonorrhoea infection in infertile populations. Current infection prevalence was several folds higher than that in the general population; the global estimate in infertile populations was $2.2 \%$, compared with only $0.8 \%$ in the general population (per WHO 2016 estimates). ${ }^{11}$ Regional estimates followed a similar pattern. Current infection prevalence rates in infertile versus the general population were $5.0 \%$ vs $1.8 \%{ }^{11}$ in AFRO, $2.7 \%$ vs $0.7 \%{ }^{11}$ in EMRO, $2.5 \%$ vs $0.8 \%{ }^{11}$ in WPRO, and $2.4 \%$ vs $0.3 \%{ }^{11}$ in EURO, respectively. These findings should be seen against the expectation that infertile populations should be prone to a lower prevalence than the general population; there is higher frequency of STI testing among them, and therefore earlier detection and higher treatment coverage relative to the general population. Infertile populations may also undergo prophylactic antibiotic administration, not necessarily with testing, prior to procedures such as in vitro fertilisation/embryo transfer. ${ }^{6364}$

Higher prevalence was also associated with conditions conventionally considered as sequelae of gonorrhoea infection, ${ }^{12}$ such as TFI and secondary infertility. TFI was associated with twofold higher odds of gonorrhoea infection. The biological plausibility behind this association has been repeatedly described, with evidence showing that untreated gonococcal infection can lead to pathogen ascension to the upper genital tract, causing pelvic inflammatory disease, tubal scarring, oviduct occlusion and internal tissue adhesion. ${ }^{12} 1865$ Higher prevalence was also found in individuals with mixed and unexplained infertility diagnoses. However, samples comprising mixed infertility diagnoses often included individuals with TFI, while more studies are needed to elucidate the association with unexplained infertility. Prevalence was further higher in individuals with secondary infertility, possibly because secondary infertility is more likely to be caused by 'preventable/acquired factors', such as recurrent exposure to STIs, as opposed to primary infertility, which is more likely to be caused by non-preventable genetic/congenital abnormalities. 36667

These findings attest to the potential role of gonorrhoea, and/or possibly other STIs associated with gonorrhoea, such as chlamydia, in infertility. Since early detection and treatment of gonococcal infections have been challenged by infection's asymptomatic nature, ${ }^{68} 69$ and growing antimicrobial resistance, ${ }^{22-26}$ these findings support the global public health value of developing gonococcal vaccines ${ }^{29} 30$ as a fundamental solution to gonorrhoea's adverse implications. ${ }^{70}$ These findings also support the timeliness of a comprehensive prevention approach promoting sexual health to control N. gonorrhoeae and other STIs, mitigate antimicrobial resistance and achieve WHO global health sector strategy targets. ${ }^{21}$ Such an approach would focus on the simultaneous implementation of biomedical (rolling-out testing and vaccination), behavioural (promoting healthier sexual lives) and structural prevention interventions (improving access to testing, treatment and care services). Indeed, successful and sustainable implementation of biomedical interventions cannot be achieved without adequate levels of public awareness, access to/uptake of services, and adherence/retention in prevention and treatment cascades.

Interestingly, there was evidence of declining prevalence by $\sim 3 \%$ per year over the last four decades, possibly mirroring 
Table 2 Results of univariable metregression analyses for the prevalence of NG infection in infertile populations

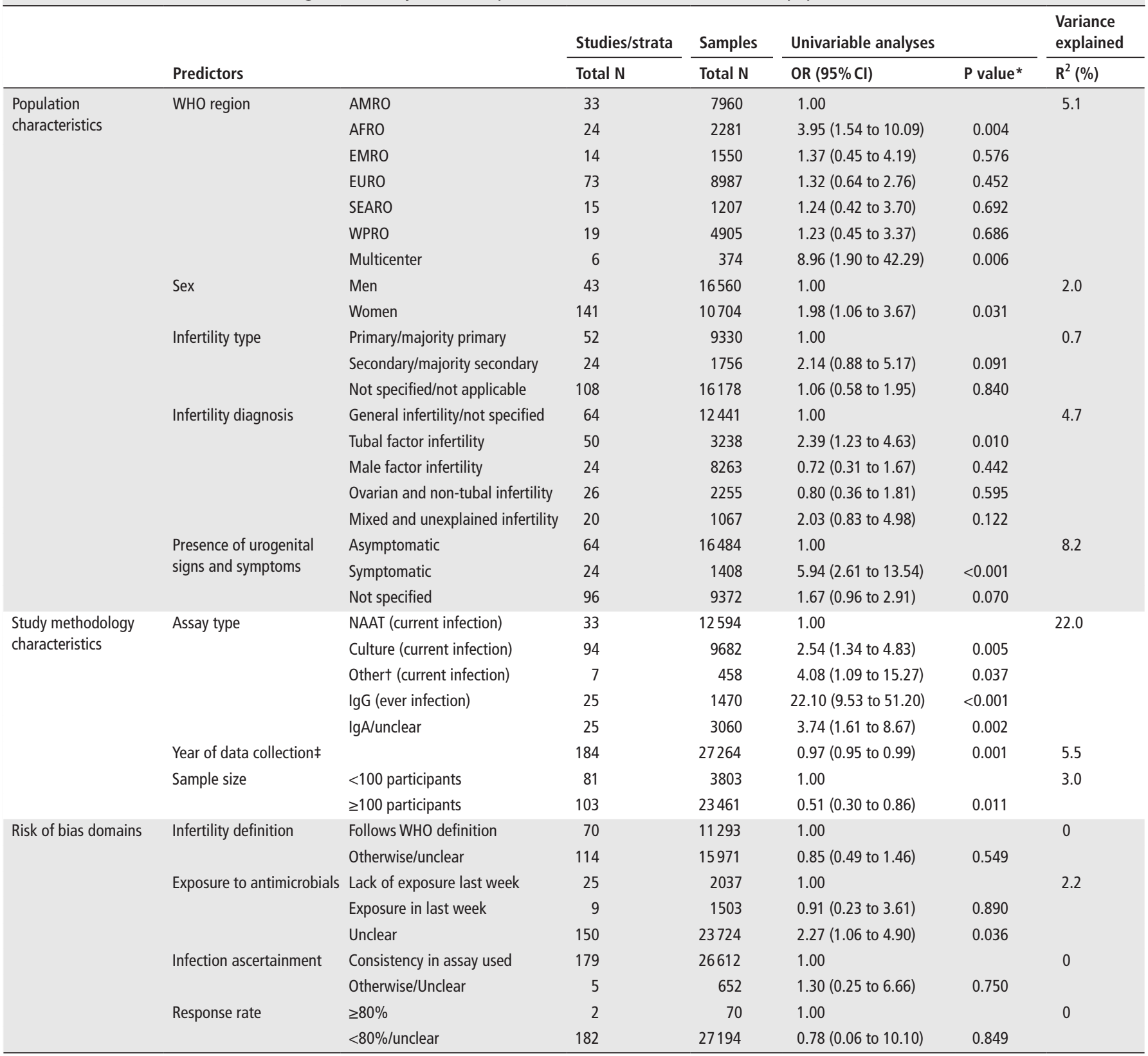

*Strength of evidence for an association with prevalence was deemed 'good' at $0.05<p$ value $\leq 0.10$, and 'strong' at $p$ value $\leq 0.05$.

†Includes Gram stain, gonozyme and fluorescent antibody assays.

¥Missing values for year of data collection were imputed using data for year of publication adjusted by the median difference between year of publication and year of data collection (for studies with complete information).

AFRO, African Region; AMRO, Region of the Americas; EMRO, Eastern Mediterranean Region; EURO, European Region; NAAT, nucleic acid amplification test; NG, Neisseria gonorrhoeae; SEARO, South-East Asia Region; WPRO, Western Pacific Region.

declines in prevalence in the population at large, ${ }^{7172}$ or growing STI testing and treatment coverage, and use of improved diagnostics in infertility workup. ${ }^{73}$ There was also evidence of regional variability in prevalence, with AFRO being most affected. This may reflect variability in background prevalence: AFRO has the highest gonorrhoea prevalence in the general population. ${ }^{11}$

The higher infection levels in infertile women compared with men, possibly reflect larger contribution of gonorrhoea to infertility in women (online supplementary figure 14) ${ }^{74}$ higher susceptibility to gonorrhoea acquisition in women ${ }^{75}$ or persistence for longer durations, as this infection is largely asymptomatic in women. ${ }^{68} 69$ As signs and symptoms are indicative of infection sequelae ${ }^{76}$ gonorrhoea prevalence was higher in symptomatic compared with asymptomatic individuals.

There were differences in prevalence by assay type, a result difficult to interpret given differences in sensitivity and specificity, ${ }^{73}$ and recent and differential use of NAAT in resource-rich versus resource-limited settings. ${ }^{73}$ Of note, the variation in the use of assays across settings and time is not likely to differentially affect one population, such as infertile populations, as opposed to another, such as the general population. While ever infection prevalence was much higher than current infection prevalence, this finding has probably limited epidemiological relevance, 


\section{Key messages}

- Current gonorrhoea infection prevalence in infertile populations varied across regions but was several folds higher than that for the general population across world regions.

- Twice higher odds of gonorrhoea infection were found in women with tubal factor infertility and secondary infertility.

- A fraction of observed infertility is possibly preventable by controlling Neisseria gonorrhoeae transmission.

given cross-reaction with other pathogens, such as Staphylococcus aureus. ${ }^{7377} 78$

Our study has unavoidable limitations. Data quantity and quality varied across regions and sometimes limited our ability to produce representative summary estimates; there were only six studies assessing current infection in SEARO, all from India. It was not possible to conduct full multivariable metaregression to adjust for potential confounders, with the large number of predictors relative to that of studies. Prevalence estimates by infertility diagnosis may have been affected by unavoidable overlap across categories; samples with mixed infertility often included TFI, and those with non-TFI may have included other infertility diagnoses. An analysis by age could not be performed, given the low number of studies reporting patients' age. There was evidence for small-study effect in metaregression (table 2 and online supplementary table 12), suggesting publication bias; studies with small sample size reported higher prevalence. Conversely, differential access to quality STI testing and treatment in infertility clinics, in settings with better versus limited access to STI services, may have biassed such studies towards lower prevalence. ${ }^{10}{ }^{79-81}$ Risk of bias assessment was limited by studies with missing information. Gonorrhoea prevalence was often reported as a secondary outcome, with no 'gonorrhoea' term listed in title/abstract, thereby complicating study identification.

In conclusion, gonorrhoea prevalence in infertile populations is several folds higher than that in the general population. This finding, along with even higher prevalence in women with TFI and individuals with secondary infertility, attests to the potential role of $\mathrm{N}$. gonorrhoeae in infertility and suggests that a fraction of infertility is possibly preventable by controlling $N$. gonorrhoeae transmission. Expansion of N. gonorrhoeae surveillance and monitoring in infertile populations is warranted as gaps in evidence persist. A multifaceted response should be considered to ensure progress towards WHO global health sector strategy targets. $^{21}$

\section{Author affiliations \\ IInfectious Disease Epidemiology Group, Weill Cornell Medicine-Qatar, Cornell University, Qatar Foundation-Education City, Doha, Qatar \\ ${ }^{2}$ Department of Public Health, College of Health Sciences, Academic Quality Affairs Office, QU Health, Qatar University, Doha, Qatar \\ ${ }^{3}$ Department of Reproductive Health and Research, World Health Organization, Geneva, Switzerland \\ ${ }^{4}$ Faculty of Medicine and Health Sciences, Ghent University, Ghent, Belgium ${ }^{5}$ Department of Obstetrics \& Gynaecology, Stellenbosch University, Stellenbosch, South Africa \\ ${ }^{6}$ Department of Healthcare Policy and Research, Weill Cornell Medicine, Cornell University, New York, New York, USA}

Acknowledgements The authors thank Ms Adona Canlas for her assistance with locating full-text articles and Professor Nico Nagelkerke for statistical analysis support.
Contributors HC contributed to the study design, conducted the systematic searches of the literature, selected studies for inclusion, performed data extraction and data analyses, and wrote the first draft of the paper. AM contributed to title and abstract screening, full-text screening and data extraction. FAH double extracted the data. IT and LJA conceived and led the design of the study. LJA led the data extraction, analyses and drafting of the article. KB, JK, and TCM contributed to the study design. All authors contributed to the discussion and interpretation of the results and to the writing of the article, and have read and approved the final manuscript.

Funding This work was supported by funding from the WHO. This work was also funded by the UNDP-UNFPA-UNICEF-WHO-World Bank Special Programme of Research, Development and Research Training in Human Reproduction, a cosponsored programme executed by the WHO. JK and IT are staff members of the WHO. The authors alone are responsible for the views expressed in this publication, and they do not necessarily represent the views, decisions or policies of the WHO.

Disclaimer The authors alone are responsible for the views expressed in this publication and they do not necessarily represent the views, decisions or policies of the WHO.

Competing interests The authors have no conflicts of interests to declare.

Patient consent for publication Not required.

Provenance and peer review Not commissioned; internally peer reviewed.

Data availability statement All data relevant to the study are included in the article or uploaded as supplementary information. All data are available as part of the manuscript and its supplementary material.

Open access This is an open access article distributed in accordance with the Creative Commons Attribution Non Commercial (CC BY-NC 4.0) license, which permits others to distribute, remix, adapt, build upon this work non-commercially, and license their derivative works on different terms, provided the original work is properly cited, appropriate credit is given, any changes made indicated, and the use is non-commercial. See: http://creativecommons.org/licenses/by-nc/4.0/.

\section{ORCID iD}

Laith J Abu-Raddad http://orcid.org/0000-0003-0790-0506

\section{REFERENCES}

1 Zegers-Hochschild F, Adamson GD, Dyer S, et al. The International glossary on infertility and fertility care, 2017. Fertil Steril 2017;108:393-406.

2 World Health Organization. Multiple definitions of infertility, 2019. Available: https:// wwwwhoint/reproductivehealth/topics/infertility/multiple-definitions/en/ [Accessed 7th Jul 2019].

3 Mascarenhas MN, Flaxman SR, Boerma T, et al. National, regional, and global trends in infertility prevalence since 1990: a systematic analysis of 277 health surveys. PLoS Med 2012;9:e1001356

4 Inhorn MC, Patrizio P. Infertility around the globe: new thinking on gender, reproductive technologies and global movements in the 21 st century. Hum Reprod Update 2015:21:411-26.

5 Agarwal A, Mulgund A, Hamada A, et al. A unique view on male infertility around the globe. Reproductive biology and endocrinology : RB\&E 2015;13:37.

6 Newman L, Rowley J, Vander Hoorn S, et al. Global estimates of the prevalence and incidence of four curable sexually transmitted infections in 2012 based on systematic review and global reporting. PloS one 2015;10:e0143304

7 Davies B, Turner KME, Frølund M, et al. Risk of reproductive complications following Chlamydia testing: a population-based retrospective cohort study in Denmark. Lancet Infect Dis 2016;16:1057-64.

8 Broeze KA, Opmeer BC, Coppus SFPJ, et al. Chlamydia antibody testing and diagnosing tubal pathology in subfertile women: an individual patient data metaanalysis. Hum Reprod Update 2011;17:301-10.

9 Land JA, Evers JL, Goossens VJ. How to use Chlamydia antibody testing in subfertility patients. Hum Reprod 1998:13:1094-8.

10 Smolak A, Chemaitelly H, Hermez JG, et al. Epidemiology of Chlamydia trachomatis in the middle East and North Africa: a systematic review, meta-analysis, and metaregression. Lancet Glob Health 2019;7:e1197-225.

11 Rowley J, Vander Hoorn S, Korenromp E, et al. Chlamydia, gonorrhoea, trichomoniasis and syphilis: global prevalence and incidence estimates, 2016. Bull World Health Organ 2019:97:548-62.

12 Lenz JD, Dillard JP. Pathogenesis of Neisseria gonorrhoeae and the Host Defense in Ascending Infections of Human Fallopian Tube. Front Immunol 2018:9:2710.

13 Simms I, Stephenson JM. Pelvic inflammatory disease epidemiology: what do we know and what do we need to know? Sex Transm Infect 2000;76:80-7.

14 Ness RB, Markovic N, Carlson CL, et al. Do men become infertile after having sexually transmitted urethritis? an epidemiologic examination. Fertil Steril 1997:68:205-13.

15 Ochsendorf FR. Sexually transmitted infections: impact on male fertility. Andrologia 2008;40:72-5 
16 Wang YC, Chung $\mathrm{CH}$, Chen JH, et al. Gonorrhea infection increases the risk of prostate cancer in Asian population: a nationwide population-based cohort study. European journal of clinical microbiology \& infectious diseases : official publication of the European Society of Clinical Microbiology 2017;36:813-21.

17 Trojian TH, Lishnak TS, Heiman D. Epididymitis and orchitis: an overview. Am Fam Physician 2009;79:583-7.

18 Tsevat DG, Wiesenfeld HC, Parks C, et al. Sexually transmitted diseases and infertility. Am J Obstet Gynecol 2017;216:1-9.

19 Cui W. Mother or nothing: the agony of infertility. Bull World Health Organ 2010;88:881-2

20 Katz P, Showstack J, Smith JF, et al. Costs of infertility treatment: results from an 18-month prospective cohort study. Fertility and sterility 2011;95:915-21.

21 World Health Organization. Global health sector strategy on sexually transmitted infections, 2016-2021. Available: http://apps.who.int/iris/bitstream/handle/10665/ 246296/WHO-RHR-16.09-eng.pdf;jsessionid=51BFC17A28B76FCF246AACEB F08826DD? sequence $=1$

22 Suay-Garcia B, Perez-Gracia MT. Future prospects for Neisseria gonorrhoeae treatment. Antibiotics 2018;7.

23 Wi T, Lahra MM, Ndowa F, et al. Antimicrobial resistance in Neisseria gonorrhoeae: global surveillance and a call for international collaborative action. PLoS Med 2017; 14:e1002344.

24 Lewis DA. Global resistance of Neisseria gonorrhoeae: when theory becomes reality. Curr Opin Infect Dis 2014;27:62-7.

25 Bolan GA, Sparling PF, Wasserheit JN. The emerging threat of untreatable gonococcal infection. N Engl J Med 2012;366:485-7.

26 Kirkcaldy RD, Harvey A, Papp JR, et al. Neisseria gonorrhoeae Antimicrobial Susceptibility Surveillance - The Gonococcal Isolate Surveillance Project, 27 Sites, United States, 2014. MMWR Surveill Summ 2016;65:1-19.

27 World Health Organization. Global action plan to control the spread and impact of antimicrobial resistance in Neisseria gonorrhoeae, 2012.

28 Ndowa F, Lusti-Narasimhan M, Unemo M. The serious threat of multidrug-resistant and untreatable gonorrhoea: the pressing need for global action to control the spread of antimicrobial resistance, and mitigate the impact on sexual and reproductive health. Sex Transm Infect 2012;88:317-8.

29 Gonococcal Vaccine PPC Expert Advisory Group. Gonococcal vaccines: public health value and preferred product characteristics - report of who global Stakeholder consultation, January 2019. Geneva, Switzerland, 2019.

30 Edwards JL, Jennings MP, Seib KL. Neisseria gonorrhoeae vaccine development: hope on the horizon? Curr Opin Infect Dis 2018;31:246-50.

31 Reekie J, Donovan B, Guy R, et al. Risk of ectopic pregnancy and tubal infertility following gonorrhea and Chlamydia infections. Clin Infect Dis 2019;69:1621-3.

32 Fowler T, Caley M, Johal R, et al. Previous history of gonococcal infection as a risk factor in patients presenting with gonorrhoea. Int J STD AIDS 2010;21:277-8.

33 Hosenfeld CB, Workowski KA, Berman S, et al. Repeat infection with Chlamydia and gonorrhea among females: a systematic review of the literature. Sex Transm Dis 2009:36:478-89.

34 Walker CK, Sweet RL. Gonorrhea infection in women: prevalence, effects, screening, and management. Int J Womens Health 2011;3:197-206.

35 Burstein GR, Eliscu A, Ford K, et al. Expedited partner therapy for adolescents diagnosed with Chlamydia or gonorrhea: a position paper of the Society for adolescent medicine. Journal of Adolescent Health 2009;45:303-9.

36 Whittington WL, Kent C, Kissinger P, et al. Determinants of persistent and recurrent Chlamydia trachomatis infection in young women: results of a multicenter cohort study. Sex Transm Dis 2001;28:117-23.

37 Golden MR, Whittington WLH, Handsfield HH, et al. Effect of expedited treatment of sex partners on recurrent or persistent gonorrhea or chlamydial infection. N Engl J Med 2005;352:676-85.

38 Rose SB, Garrett SM, Stanley J, et al. Chlamydia trachomatis and Neisseria gonorrhoeae retesting and reinfection rates in New Zealand health care settings: implications for sexually transmitted infection control. Sex Transm Dis 2020;47:151-7.

39 Low N, Heijne JCM, Herzog SA, et al. Reinfection by untreated partners of people treated for Chlamydia trachomatis and Neisseria gonorrhoeae: mathematical modelling study. Sex Transm Infect 2014;90:254-6.

40 Gunn RA, Fitzgerald S, Aral SO. Sexually transmitted disease clinic clients at risk for subsequent gonorrhea and chlamydia infections: possible 'core' transmitters. Sex Transm Dis 2000;27:343-9.

41 Radcliffe K, Ahmed-Jushuf I, Cowan F, et al. Uk national guidelines on sexually transmitted infections and closely related conditions. Introduction. Sex Transm Infect 1999;75:S2-3

42 O'Connell CM, Brochu H, Girardi J, et al. Simultaneous profiling of sexually transmitted bacterial pathogens, microbiome, and concordant host response in cervical samples using whole transcriptome sequencing analysis. Microb Cell 2019;6:177-83.

43 Kouyoumjian SP, Heijnen M, Chaabna K, et al. Global population-level association between herpes simplex virus 2 prevalence and HIV prevalence. AIDS 2018;32:1343-52
44 Abu-Raddad LJ, Schiffer JT, Ashley R, et al. Hsv-2 serology can be predictive of HIV epidemic potential and hidden sexual risk behavior in the middle East and North Africa. Epidemics 2010;2:173-82.

45 Omori R, Abu-Raddad LJ. Sexual network drivers of HIV and herpes simplex virus type 2 transmission. AIDS 2017;31:1721-32.

46 Omori R, Nagelkerke N, Abu-Raddad LJ. Hiv and herpes simplex virus type 2 epidemiological synergy: misguided observational evidence? A modelling study. Sex Transm Infect 2018;94:372-6.

47 Aral SO. Sexual risk behaviour and infection: epidemiological considerations. Sex Transm Infect 2004;80:iï-12.

48 Barry PM, Kent CK, Klausner JD. Risk factors for gonorrhea among heterosexuals--San Francisco, 2006. Sex Transm Dis 2009;36:S62-6.

49 Hughes $\mathrm{G}$, Field $\mathrm{N}$. The epidemiology of sexually transmitted infections in the UK: impact of behavior, services and interventions. Future Microbiol 2015;10:35-51.

50 Warszawski J, Meyer L. Gender difference in persistent at-risk sexual behavio after a diagnosed sexually transmitted disease. ACSF-Investigators. Sex Transm Dis 1998;25:437-42.

51 Ashenhurst JR, Wilhite ER, Harden KP, et al. Number of sexual partners and relationship status are associated with unprotected sex across emerging adulthood. Arch Sex Behav 2017;46:419-32.

52 Dariotis JK, Sonenstein FL, Gates GJ, et al. Changes in sexual risk behavior as young men transition to adulthood. Perspect Sex Reprod Health 2008;40:218-25.

53 Chemaitelly H, Harfouche M, Blondeel K, et al. Global epidemiology of Neisseria gonorrhoeae in infertile populations: protocol for a systematic review. BMJ Open 2019;9:e025808

54 Higgins JPT, Green S, Cochrane Collaboration. Cochrane Handbook for systematic reviews of interventions. Chichester, England; Hoboken, NJ: Wiley-Blackwell, 2008.

55 Moher D, Liberati A, Tetzlaff J, et al. Preferred reporting items for systematic reviews and meta-analyses: the PRISMA statement. PLoS Med 2009;6:e1000097.

56 Khadr L, Harfouche M, Omori R, et al. The epidemiology of herpes simplex virus type 1 in Asia: systematic review, meta-analyses, and meta-regressions. Clinical infectious diseases : an official publication of the Infectious Diseases Society of America 2018

57 Mumtaz GR, Weiss HA, Thomas SL, et al. Hiv among people who inject drugs in the middle East and North Africa: systematic review and data synthesis. PLOS Med 2014:11:e1001663.

58 Chaabane S, Harfouche M, Chemaitelly H, et al. Herpes simplex virus type 1 epidemiology in the middle East and North Africa: systematic review, meta-analyses, and meta-regressions. Sci Rep 2019;9:1136.

59 Kouyoumjian SP, Chemaitelly H, Abu-Raddad LJ. Characterizing hepatitis C virus epidemiology in Egypt: systematic reviews, meta-analyses, and meta-regressions. SC Rep 2018:8:1661.

60 Higgins JPT, Thompson SG. Quantifying heterogeneity in a meta-analysis. Stat Med 2002;21:1539-58

61 Borenstein M. Introduction to meta-analysis. Chichester, U.K.: John Wiley \& Sons, 2009

62 Babyak MA. What you see may not be what you get: a brief, nontechnical introduction to overfitting in regression-type models. Psychosom Med 2004;66:411-21.

63 Pereira N, Hutchinson AP, Lekovich JP, et al. Antibiotic prophylaxis for gynecologic procedures prior to and during the utilization of assisted reproductive technologies: a systematic review. J Pathog 2016;2016:1-8.

64 Brook N, Khalaf Y, Coomarasamy A, et al. A randomized controlled trial of prophylactic antibiotics (co-amoxiclav) prior to embryo transfer. Hum Reprod 2006;21:2911-5.

65 Briceag I, Costache A, Purcarea VL, et al. Fallopian tubes--literature review of anatomy and etiology in female infertility. J Med Life 2015:8:129-31.

66 Centers for Disease Prevention and Control. Infertility and sexually transmitted diseases 2000-2003, 2004. Available: https://www.cdc.gov/std/infertility/reportcongre ssinfertility.pdf

67 Menon S, Timms P, Allan JA, et al. Human and pathogen factors associated with Chlamydia trachomatis-Related infertility in women. Clin Microbiol Rev 2015:28:969-85

68 Johnson LF, Geffen N. A comparison of two mathematical modeling frameworks for evaluating sexually transmitted infection epidemiology. Sex Transm Dis 2016:43:139-46

69 Korenromp EL, Sudaryo MK, de Vlas SJ, et al. What proportion of episodes of gonorrhoea and Chlamydia becomes symptomatic? Int J STD AIDS 2002;13:91-101

70 Ndowa F, Lusti-Narasimhan M. The threat of untreatable gonorrhoea: implications and consequences for reproductive and sexual morbidity. Reprod Health Matters 2012:20:76-82.

71 Peterman TA, O'Connor K, Bradley HM, et al. Gonorrhea control, United States, 19722015, a narrative review. Sex Transm Dis 2016;43:725-30.

72 Cribier B, Asch PH, Tardieu JC. Declining rates of gonorrhoea and syphilis in Strasbourg, France: a 20-year study. Genitourin Med 1994;70:273-7.

73 Gaydos C, Hardick J. Point of care diagnostics for sexually transmitted infections: perspectives and advances. Expert Rev Anti Infect Ther 2014;12:657-72

74 Apari $P$, de Sousa JD, Müller V. Why sexually transmitted infections tend to cause infertility: an evolutionary hypothesis. PLoS Pathog 2014;10:e1004111. 
75 Wong T, Singh A, Mann J, et al. Gender differences in bacterial STIs in Canada. BMC Womens Health 2004;4:\$26.

76 Hill SA, Masters TL, Wachter J. Gonorrhea - an evolving disease of the new millennium. Microb Cell 2016;3:371-89.

77 Centers for Disease Control and Prevention. Recommendations for the laboratorybased detection of Chlamydia trachomatis and Neisseria gonorrhoeae-2014. MMWR Recommendations and reports : Morbidity and mortality weekly report Recommendations and reports 2014;63:1-19.

$78 \mathrm{Ng} \mathrm{L-K}$, Martin IE. The laboratory diagnosis of Neisseria gonorrhoeae. Can J Infect Dis Med Microbiol 2005;16:15-25.
79 Ozolins D, D'Elios MM, Lowndes CM, et al. Diagnostics, surveillance and management of sexually transmitted infections in Europe have to be improved: lessons from the European conference of national strategies for Chlamydia trachomatis and human papillomavirus (NSCP conference) in Latvia, 2011. J Eur Acad Dermatol Venereol 2013;27:1308-11.

80 Bingham AL, Kavanagh AM, Fairley CK, et al. Income inequality and Neisseria gonorrhoeae notifications in females: a country-level analysis. Sex Health 2014;11:556-60.

81 Hazel A, Ponnaluri-Wears S, Davis GS, et al. High prevalence of Neisseria gonorrhoeae in a remote, undertreated population of Namibian pastoralists. Epidemiol Infect 2014;142:2422-32. 